\title{
REVISÃO
}

\section{Células natural killer e efeito do treinamento}

\author{
Natural killer cells and effect of training
}

Grasiely Faccin Borges, M.Sc.*, Ana Maria Miranda Botelho Teixeira, D.Sc.**, Luís Manuel Pinto Lopes Rama, D.Sc.***

*Professora do Instituto de Saúde e Biotecnologia da Universidade Federal do Amazonas, Doutoranda em Ciências do Desporto na Universidade de Coimbra, Portugal, Instituto de Saúde e Biotecnologia da Universidade Federal do Amazonas, **Professora e Pesquisadora do Centro de Investigação do Desporto e da Actividade Física da Faculdade de Ciências do Desporto e Educação Física e Coordenadora do Doutorado em Ciências do Desporto da Universidade de Coimbra, Portugal, ***Professor e Pesquisador do Centro de Investigação do Desporto e da Actividade Física da Faculdade de Ciências do Desporto e Educação Física da Universidade de Coimbra, Portugal

\section{Resumo}

As células natural killer (NK) possuem um importante papel na imunidade inata e tanto sua quantidade quanto a sua atividade no sangue periférico sofrem uma grande flutuação durante e após o exercício físico. O objetivo desta revisão foi verificar a resposta das células NK após o treinamento. Para a busca dos estudos utilizou-se as bases de dados eletrônicos National Library of Medicine (Medline/PubMed), Literatura Latino-americana e do Caribe em Ciência da Saúde (Lilacs) e Scientific Electronic Library Online (Scielo) e Sport Discus.
Os descritores utilizados foram: exercise, CD56, Natural killer e NK. Treze estudos foram selecionados para esta revisáo, nove deles apresentaram um aumento significativo no número de células NK circulantes. O treinamento pode induzir uma redistribuição das células NK que pode ser observada logo após o término do exercício, podendo refletir um processo de recuperação e adaptaçáo, em resposta ao estresse fisiológico.

Palavras-chaves: células matadoras naturais, subpopulações de linfócitos, exercício, sistema imunológico.

Recebido em 23 de novembro de 2012; aceito em 4 de fevereiro de 2013.

Endereço para correspondência: Grasiely Faccin Borges, Faculdade de Ciências do Desporto e Educação Física Estádio Universitário - Pavilhão III, Santa Clara, 3040-156 Coimbra Portugal, Tel: (351) 239-802770,E-mail: gfborge@ufam.edu.br 


\section{Abstract}

Natural killer cells (NK) cells have an important role in innate immunity with both their number and activity in peripheral blood undergoing large fluctuations during and after exercise. The purpose of this literature review was to identify the effect of training on natural killer cells (NK). Were used the electronic databases National Library of Medicine (Medline / PubMed), Latin American and Caribbean on Health Sciences (Lilacs), Scientific Electronic Library Online (Scielo) and
Sport Discus. The descriptors used were: exercise, CD56, Natura killer and NK. Thirteen studies were selected, nine of them showed a significant increase in the number of circulating NK cells. Training may induce a redistribution of NK cells that could be seen after the exercise, which may reflect a process of recovery and adaptation in response to physiological stress.

Key-words: killer cells, lymphocyte subsets, exercise, imune system.

\section{Introdução}

As células Natural Killer (NK) têm atraído a atenção dos pesquisadores na área da fisiologia do exercício, pois tanto o seu número quanto a sua atividade no sangue periférico sofrem uma grande flutuação durante e após o exercício físico. Novos dados sobre a origem, desenvolvimento, e interação destas células com outros fatores imunológicos e não-imunológicos têm surgido [1,2] e representam um campo com rápido desenvolvimento de pesquisas, que tem explorado o significado das alteraçóes nas células NK induzidas pelo exercício físico.

As células NK fazem parte da imunidade inata, elas exibem o receptor para a interleucina 2 (IL-2R), CD16 e CD56 e náo expressam o $\mathrm{CD} 3$. O marcador CD56 é considerado o principal marcador deste tipo de célula, esse existe também em outros tipos de células, incluindo NK e subpopulaçóes de linfócitos T normalmente denominados células NKT $\left(\mathrm{CD} 3{ }^{+} \mathrm{CD} 56^{+}\right)$, tecido neural adulto e muscular, bem como em tecidos embrionários [3-5]. Internacionalmente são aceitos e utilizados como marcadores do fenótipo das células NK o $\mathrm{CD} 3{ }^{-} \mathrm{CD} 16^{+} \mathrm{CD} 56^{+}$. Algumas células apresentam a ausência do marcador $\mathrm{CD}_{16} 6^{+} \mathrm{e}$ possuem uma atividade citolítica natural, incluindo também uma pequena população de $\mathrm{CD}^{+} \mathrm{CD}^{+} 6^{+}$, o $\mathrm{CD} 57^{+}$constitui também outro marcador utilizado para identificação dessas células $[1,2,6,7]$.
As células NK imaturas diferenciam-se, fenotipicamente e funcionalmente, em células NK maduras após a aquisição do $\mathrm{CD} 56^{+} \mathrm{e}$ o aparecimento do pontencial citolítico. A expressão do complexo CD94/NKG2A surge mais tarde, antes da etapa final, que culmina com a expressão de $\mathrm{CD}_{16} 6^{+}$e de receptores específicos para moléculas MHC-I clássico, os KIR. As células NK são derivadas das células progenitoras hematopoiéticas $\mathrm{CD} 34^{+}$e o processo de maturação permite classificá-las em duas subpopulaçôes: as que expressam níveis elevados de $\mathrm{CD} 56^{+}$conhecidas como CD$56^{\text {bright }}$, ou as que expressam níveis reduzidos chamadas de CD 56 $6^{\text {dim }}[1,2]$. As células natural killer (NK) possuem um importante papel na primeira linha de defesa contra micro-organismos e certos tipos de células tumorais. Sáo características das CD3-, e linfócitos CD56+ expressar atividade de células assassinas ativadas por linfocina (LAK) ao serem estimuladas por IL-2 e secretando citocinas como o IFN- $\gamma$ [7-9]. Existem tipos de células tumorais positivas para CD56 incluindo alguns tipos de leuceminas mielóides, mielomas, neuroblastomas, tumores de Wilm, tumores e pequenas células cancerígenas $[3,4,10]$. $\mathrm{O}$ receptor IL-2 parece ativar preferencialmente

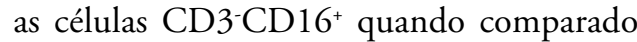
com a populaçáo $\mathrm{CD} 3{ }^{-} \mathrm{CD} 56^{+}$, no entanto o receptor IL-15 ativa uma maior percentagem de $\mathrm{CD} 3{ }^{-} \mathrm{CD} 56^{+}$[5]. A atividade citolítica das células NK é reforçada pelo interferon-alfa e pela interleucina-2 [11], enquanto que certas prostagandinas [12] e inunocomplexos 
regulam negativamente a função das NK. As células NK são também dotadas de funçôes imunoreguladoras, uma vez que segregam citocinas tais como IFN- $\gamma$, que favorecem o desenvolvimento das células T helper 1 (Th1), e as quimiocinas, tais como CCL3/MIP- $1 \alpha$ e CCL4/MIP-1 $\beta$, que recrutam várias células inflamatórias para locais de inflamação $[8,13]$.

Com o aumento das pesquisas sobre o exercício físico e as células natural killer, algumas questôes têm sido respondidas enquanto que outras ainda continuam obscuras [14]. Alguns pesquisadores têm assumido que o aumento no número ou atividade no sangue periférico das natural killer seria benéfico, baseando-se em evidências experimentais, através das quais é possível verificar que uma fração de células mononucleares contendo células NK seriam capazes de destruir certas linhas de células cancerígenas ou células infectadas por vírus, no entanto é necessário observar cuidadosamente esses resultados, visto que em resultados clínicos, em pacientes com deficiência nas células NK, e com uma variedade de defeitos genéticos, foi demonstrado que essas células não são super armas e que possuem uma faixa relativamente estreita de possíveis alvos $[15,16]$.

As pesquisas sobre o exercício e/ou treino e as células NK têm normalmente incluído estudos transversais e longitudinais $[7,14]$. Os estudos transversais sobre esse tema levam em consideração que os efeitos residuais da prática de exercícios físicos regulares podem ser sustentados por muitos anos. No entanto a validade desse tipo de comparação é ameaçado pela diferença entre o estilo de vida de atletas de alto rendimento e a população sedentária geral, que sendo distintas apresentam muitas vezes resultados de difícil interpretação. Além disso, problemas metodológicos em muitos estudos, como, por exemplo, a falta de atenção dada ao período de descanso utilizado antes da coleta de sangue que é utilizada, após a realização do exercício, tem contribuído para a dificuldade em comparar resultados uma vez que o efeito sobre as células NK podem persistir por 3 dias ou mais [18].

Apesar de existirem evidências sobre as células NK e o exercício físico agudo [7], ainda existem lacunas no que diz respeito à compreensão das alteraçôes ocorridas com as células NK após períodos de treino regular, constituindo este aspecto o principal objetivo deste artigo, onde por meio de uma revisão sistemática buscou-se explorar o efeito do treinamento sobre o comportamento das células natural killer (NK).

\section{Métodologia}

Inicialmente realizou-se uma busca na literatura utilizando os seguintes descritores em inglês: exercise, CD56, Natura killer, NK, Para a busca dos estudos utilizou-se as bases de dados eletrônicas National Library of Medicine (Medline/PubMed), Literatura Latino-Americana e do Caribe em Ciência da Saúde (Lilacs) e Scientific Electronic Library Online (Scielo) e Sport Discus.

Para a seleção dos estudos foi estabelecido os seguintes critérios de inclusão: 1) avaliar as células natural killer, apresentado valores em percentuais ou número absoluto de células; 2) o exercício físio e/ou treino estar definido claramente (ex. número de repetiçôes e/ou duração) do exercício ou treino; 3) ter na amostra indivíduos do sexo masculino, saudáveis, visto que indivíduos do sexo feminino possuem respostas diferentes das células NK em resposta ao exercício físico [19,20]; 4) avaliar indivíduos adultos, pois levamos em consideraçáo que o processo de envelhecimento poderia influenciar os resultados dos estudos [21,22]; 5) os sujeitos incluídos nas amostra não deveriam estar utilizando medicamentos ou suplementação nutricional; 6) foram incluídos os artigos publicados a partir do ano de 1990, pelo motivo da rápida evoluçáo e mudanças sobre o tema.

Os procedimentos para análise dos estudos foram organizados na seguinte sequência: na primeira etapa, realizou-se um levantamento de artigos encontrados com os descritores propostos; na segunda, ocorreu uma leitura e seleção criteriosa dos artigos para a formação de um banco de dados sistematizado. Os dados de todos os artigos incluídos foram coletados e armazenados em novo banco de dados, 
Tabela I - Estudos selecionados sobre a resposta das células natural killer no sangue periférico após a realizaçāo de treinamento.

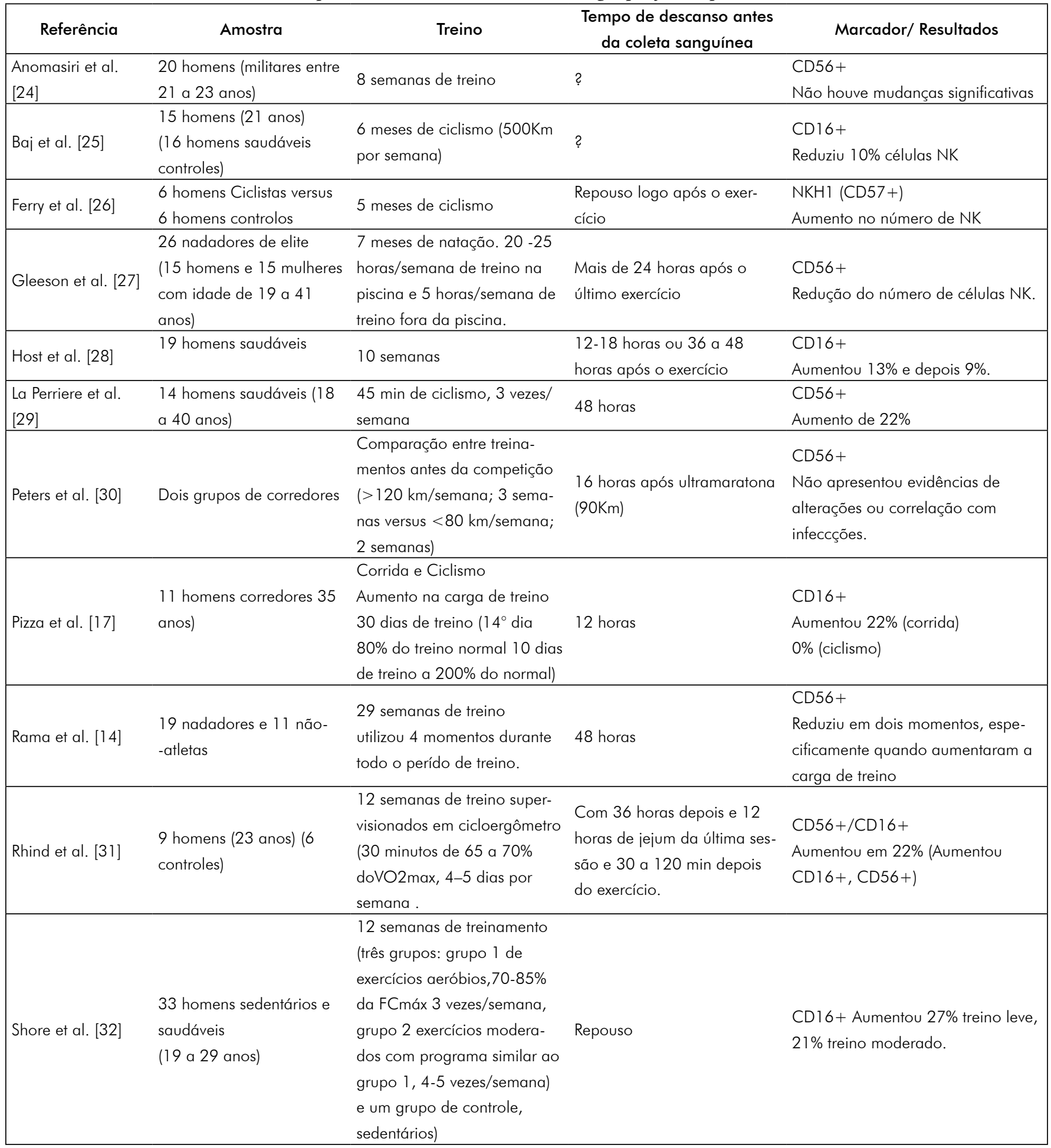




\begin{tabular}{|c|c|c|c|c|}
\hline Referência & Amostra & Treino & $\begin{array}{c}\text { Tempo de descanso antes } \\
\text { da coleta sanguínea }\end{array}$ & Marcador/ Resultados \\
\hline Tvede et al. [33] & $\begin{array}{l}29 \text { homens bem treinados } \\
\text { ciclistas ( } 23 \text { anos) e } 15 \\
\text { ciclistas não treinados }\end{array}$ & $\begin{array}{l}\text { alta e baixa intensidade de } \\
\text { treino de ciclismo }\end{array}$ & 20 horas & $\begin{array}{l}\text { CD16+ } \\
\text { NK foi significativamente mais alta } \\
\text { nos ciclistas treinados }(n=15) \\
\text { do que nos não treinados ( } n= \\
\text { 10) tanto no período de treino de } \\
\text { baixa intensidade }(39,2 \pm 11,6 \% \text { vs } \\
30,9 \pm 6,4 \% \text { ) enquanto no de alta } \\
\text { intensidade }(55,2 \pm 18.4 \% \text { vs } 33,6 \\
\pm 20,3 \%) \text {. }\end{array}$ \\
\hline Unal et al. [34] & $\begin{array}{l}24 \text { estudantes univer- } \\
\text { sitários sedentários e } \\
\text { trabalhadores }\end{array}$ & $\begin{array}{l}8 \text { semanas ( } 3 \text { vezes por } \\
\text { semana) Comparação entre } \\
\text { diferentes tipos de treinos } \\
\text { (30min x } 20 \mathrm{~min} \text { ) }\end{array}$ & ? & $\begin{array}{l}\text { CD56+ } \\
\text { Aumento de 65\% em CD56+ no } \\
\text { grupo com maior volume de treino }\end{array}$ \\
\hline
\end{tabular}

além das características sociodemográficas da população estudada: ano, tipo de estudo, formas de coletas de dados, autores, entre outras variáveis que se mostraram interessantes para essa investigação.

Como critério de exclusão para esse estudo utilizou-se: artigos em outros idiomas que não português ou inglês; trabalhos científicos divulgados em outras formatações (ex.resumos apresentados em eventos, livros etc.). Ressalta-se ainda que se tomou a precaução necessária para que os artigos não fossem incluídos duas vezes, caso estivessem indexados em várias bases de dados selecionadas.

\section{Resultados e discussão}

A partir da seleção dos artigos foram incluídos nesta revisão 13 estudos, que foram publicados entre os anos de 1995 a 2012. No quadro I estão apresentados detalhes dos estudos selecionados, como o primeiro autor e ano, constituição da amostra, treinamento realizado, tempo de descanso após o último treino antes da coleta sanguínea, o marcador que foi utilizado para determinação das células NK e os principais resultados que foram encontrados.

Durante a fase de análise dos estudos foram excluídos 4 estudos que avaliaram somente indivíduos do sexo feminino. Um estudo que avaliou adolescentes, entre $13 \mathrm{e}$ 14 anos de idade [23], também foi excluído.
Nos estudos que apresentavam informaçóes das NK durante a realização do exercício físico, optou-se especificamente por incluir, apresentar e discutir os dados referentes as coletas realizadas após o exercício físico/treino.

A maioria dos estudos selecionados incluiu no treinamento diversos tipos de exercícios, no entanto o mais citado foi o ciclismo seguido pela corrida. O marcador mais utilizado para identificar as células $\mathrm{NK}$ foi o $\mathrm{CD} 56^{+}$seguido pelo $\mathrm{CD} 16^{+}$, e alguns estudos utilizaram ambos marcadores. Apenas 2 estudos realizaram a coleta do sangue após as 48 horas de repouso (Tabela I).

Apesar dos estudos selecionados fazerem um relato da resposta do treino a longo prazo, muitos também acompanharam a resposta aguda, dessa forma foi possível verificar que o comportamento do número de células natural killer circulantes parece aumentar durante o exercício físico, seguido por uma brusca queda, imediatamente após o exercício físico, que pode ocorrer até por volta de 30 a 50 minutos após seu término, logo em seguida inicia-se um aumento no número de células circulantes no sangue periférico e esse aumento prolonga-se por 24 horas e em muitos casos por 48 horas [17,24-34].

Nos resultados apresentados nessa revisão (tabela I), mais de 8 estudos apresentaram dados referentes a exercícios físicos realizados por mais de 6 semanas consecutivas. Nos estudos transversais, os benefícios a longo prazo do 
treinamento podem ser mascarados por uma sessão de treino recente e que podem dificultar a análise e entendimento dos resultados [7].

Nos estudos selecionados ocorreram variaçóes no tempo de repouso, que foi utilizado após a realização do exercício físico, para serem feitas as coletas de sangue periférico. Através da análise dos estudos foi possível verificar, que o tempo utilizado para coleta de sangue após o exercício físico pode influenciar nos resultados, em estudos centrados na resposta ao treino, pelo que um período de tempo após o exercício tem sido respeitado para realizar a coleta da amostra de sangue. No caso do exercício moderado, 24 horas parece ser suficiente para uma completa recuperação, mas interpretaçóes errôneas da resposta ao treino podem surgir em estudos em que a elevação destas células que ocorre na resposta aguda possa persistir por diversos dias [6,7]. $\mathrm{Na}$ metanálise realizada por Shephard e Shek [6], na maioria dos artigos investigados, os sujeitos das amostras não tiveram mais que 24 horas de recuperação, e em algumas instâncias o tempo após o exercício foi muito próximo ou muito curto em relação à última sessão de exercícios.

Por dificuldades e alguns problemas envolvendo as técnicas de análises e coleta de dados imunológicos, poucos estudos tem incluído grupo de controle [6]. A partir dos estudos selecionados observou-se que após a realização do exercício físico as células NK apresentaram um comportamento similar, pois dos 12 estudos 9 apresentaram um aumento no número de NK circulantes (tabela I). Verificou-se que durante ou logo após o exercício físico as células NK (CD16+/CD56+) circulantes no sangue periférico parecem ser encontradas em maior número e percentagem em atletas do que em não atletas e esses valores podem ser mantidos por longos períodos de tempo [35]. Um estudo que avaliou 1038 atletas na China identificou proporçôes aumentadas em atletas cerca de 20 a $40 \%$ quando comparados aos níveis normais, e as subpopulaçôes $\mathrm{CD}^{+}$, $\mathrm{CD}^{+}{ }^{+} \mathrm{CD}^{+}{ }^{+}$, e $\mathrm{CD}^{+}{ }^{+} \mathrm{CD}^{+}{ }^{+} \mathrm{T}, \mathrm{B}$, e $\mathrm{NK}$ foram todas menores nos atletas quando comparados com os valores de referência clínicos [36]. No entanto, náo foi detalhado o momento de treinamento físico em que se encontravam esses atletas.

Comumente é sugerido que o exercício induz ao aumento da quantidade de células NK a partir dos reservatórios venosos que está associada ao aumento do débito cardíaco e a uma demarginação dos linfócitos associados com a mediação da ação da adenosina monofosfato cíclica, que medeia a ação das catecolaminas e as moléculas de adesão [6]. A redução da quantidade das células NK após o exercício físico pode ser causada pela remarginação celular, quando a concentração das catecolaminas diminui para os níveis normais de repouso. No entanto, é difícil indentificar qual é o mecanismo que reduz a quantidade de células $\mathrm{NK}$ aos níveis normais. É muito postulado que as células NK migram para fora da circulação na primeira hora do exercício e esta migração é mais intensa nos exercícios vigorosos, possivelmente para dar assistência na morte celular, ocorrida como consequência de microtraumas na atividade muscular $[6,7]$.

Apesar de o exercício físico extenuante em níveis mais intensos poder causar consequências negativas para a resposta imunológica, o exercício moderado a longo prazo pode influenciar a função imunológica de forma benéfica [6]. Uma metanálise identificou que indivíduos ativos fisicamente possuem uma vantagem de $17 \%$ no número de células NK quando comparados a indivíduos sendentários [6].

Relativamente ao número de células natural killer circulantes, é interessante destacar que os exercícios muito intensos, realizados cerca de 20 a 120 minutos, com uma intensidade a 75 até $90 \%$ do pico do $\mathrm{VO}_{2}$ máximo, podem causar uma maior elevação do número de células NK, no entanto, após a prática de exercícios muito pronlongados, acima de 120 minutos e realizados até 120 dias, depois de passadas 24 horas de repouso podem ser encontrados valores muitos reduzidos no número de células NK no sangue periférico [6].

Elevada atividade ou número de células NK na circulação sanguínea não parece ser sempre favorável, no caso de pacientes com problemas dermatológicos [16,37,38]. Em 
outro estudo observou-se uma elevação no número e na atividade de NK devido a uma expansão anormal dos grandes linfócitos granulares (NK), sendo uma adaptação compensatória a um defeito na mitogênese das células $\mathrm{T}$ primárias $[15,16]$.

O elevado número de NK circulantes também pode estar relacionado com o dano muscular ocasionado pelo exercício físico e costuma ser observado em situaçóes de inadaptaçáo à carga de treino como é o caso do "overtraining" $[16,17]$. Apesar das razōes que ocasionam nas mudanças de percentuais e número das células NK provocadas pelo treinamento, existe uma tentativa de relacioná-las com a performance e/ou "overtraining" em atletas [39]. Mesmo assim, como já relatado anteriormente o tempo de recuperação parece ser um fator influenciador na resposta deste tipo de célula.

Apesar de a maioria dos estudos indicar um aumento no número das células NK circulantes (tabela I), durante as buscas foi observado que dois estudos relataram uma diminuição no número total de células NK circulantes $[25,27]$ e apenas um estudo relatou que os valores não tiveram alterações significativas [24]. Especificamente no estudo de Gleeson et al. [27], a percentagem das células NK $\left(\mathrm{CD} 16^{+} / \mathrm{CD} 56^{+}\right)$declinaram entre 30 a 40 $\%$ após 7 meses de treinamento intenso de natação e foram de 20 a $30 \%$ menores que nos não atletas [27], sendo importante lembrar que esses dados foram colhidos após 24 horas do último treino. É interessante destacar que quando o exercício é continuado por diversos dias ou de forma prolongada a quantidade de células NK pode cair a um número abaixo dos níveis iniciais [6,27].

As mudanças no sistema nervoso autônomo resultantes da prática do exercício físico, de fato parecem produzir alteraçôes no ritmo circadiano dos leucócitos, sendo capaz de induzir um aumento no número das subpopulações incluindo os granulócitos, os linfócitos e as células natural killer [40]. Esse fenômeno está associado à atividade simpática em conjunção com a produção de catecolaminas no sangue causada também pelo exercício físico [40,41].
Assim a alteração do número e da atividade das células NK pode ser um reflexo da atividade simpática independente do papel imunológico das células NK $[16,42]$. No entanto, o significado da redução da circulação das células NK, como também de outros leucócitos, induzidos pelo exercício físico para a saúde ainda é desconhecida.

Após um mês de treino de voleibol verificou-se uma redução no número e também na citotoxidade das células NK. Apesar desse resultado os atletas não relataram comportamentos ou sintomas de modo que pudessem ser considerados estarem mais suceptiveis a infecçôes [43]. A queda do número circulante das células NK após o exercício físico agudo tem sido relatada por diversos estudos $[27,44]$, uma tentativa para explicar esse efeito fisiológico como sendo uma redistribuição das células do sangue periférico resultado de treino intenso [35]. Segundo Gleeson e Bishop [44], a duraçáo e a intensidade de exercício parecem influenciar a escala e a velocidade dessa mobilização.

Dos estudos selecionados para esta revisão, apenas um apresentou resultados sobre as subpopulaçôes $\mathrm{CD} 56^{\text {bright }}$ e $\mathrm{CD} 56^{\text {dim }}$ [14], neste estudo foi relatado que quando foi aumentada a carga de treinamento reduziu o número total de células NK CD56+ circulantes, mas por outro lado ocorreu um aumento no número de células $\mathrm{CD} 56^{\text {bright }}$ e uma redução no número de células NK CD56 $6^{\mathrm{dim}}$. Sabe-se que o exercício exerce grande efeito agudo nessas subpopulaçóes [7]. O exercício físico crônico pode facilitar o turnover e a geraçáo celular, com o surgimento de novas células imaturas $[2,43]$. Os leucócitos circulantes representam apenas uma fracção muito pequena (1-2\%) de leucócitos totais. Portanto, um recrutamento circulatório seletivo das células $\mathrm{NK} \mathrm{CD} 56^{\text {+bright }}$ pode ocorrer, dependendo das mudanças no ambiente interno [43].

Investigaçôes sugerem que as células NK56 $6^{\text {bright }}$ dão origem as células CD56 dim maduras, as quais prevalecem com o fenótipo das células NK. Sendo assim, existe uma hipótese que as células $\mathrm{CD} 56^{\mathrm{dim}}$ seriam derivadas das células CD56 bright, e o exercício 
poderia induzir a mobilização desta última subpopulação, refletindo a mobilização de células $\mathrm{CD} 56^{+}$imaturas. O exercício físico agudo pode mobilizar as células CD56 bright para a circulação, provavelmente a partir do tecido linfóide onde são abundantes [1], o que faz com que o exercício físico possa ter um importante papel clínico.

No estudo de Shore et al. [32], foi evidenciado que o treinamento moderado, que seria capaz de causar um balanço energético negativo, produz um menor aumento no número de células $\mathrm{NK} \mathrm{CD}_{16}{ }^{+} \mathrm{CD} 56^{+}$, de células citotóxicas não restriras ao complexo MHC, no entanto como consequência os autores atribuíram como uma consequência negativa a diminuição dos linfócitos $\mathrm{B}$ que ocorreu resultado do treinamento realizado. Apesar desse resultado, é importante destacar que os atletas possuíam um número menor de células NK em repouso.

No entanto, o exercício total realizado pode influenciar as células NK pela via da respostas neuroendócrina. Isto é possível, pois com um aumento da carga de treino ocorre um aumento antecipatório das catecolaminas (ex. Adrenalina). As células natural killer, assim como outros linfócitos expressam receptores $\beta$-adrenergicos os quais respondem às catecolaminas aumentando o número em circulação [45]. Controversamente, o aumento da concentração do cortisol tem sido relatado em associação com uma diminuiçáo no número das células NK [46] e isto pode ser possível também pela aumentada produção de glucocorticóides como uma resposta do stress ocasionado pelo exercício.

As mundaças no número e percentual de células NK parecem ser efeitos de uma supressão protetora dos resultados do exercício físico intenso ou prolongado. As quedas ocasionadas têm sido sugeridas como deixando os atletas potencialmente susceptíveis a infecçôes virais [27]. Porém, nem todos autores concordam com essa hipótose $[7,43]$.

\section{$\overline{\text { Conclusão }}$}

Os estudos publicados e utilizados por esta revisão sistemática apontam para um efeito de redistribuição das células NK induzida pelo treino, após seu término, que pode refletir um processo de recuperação e adaptação, em resposta ao estresse fisiológico. Este comportamento pode suportar um risco acrescido da eficácia da função imune. O número e percentual de células NK circulantes parece aumentar durante o exercício físico, seguido por uma brusca queda, que pode ocorrer até por volta de 30 a 50 minutos após seu término, logo em seguida inicia-se um aumento no número de células circulantes no sangue periférico e esse aumento prolonga-se por 24 horas e em muitos casos por 48 horas, esse aumento parece estar relacionado à intensidade e ao volume do exercício que foi realizado. A resposta ao treino prolongado, por outro lado, parece ser caracterizada por uma diminuição nos níveis de células NK em repouso, podendo representar uma adaptação crônica ao treino intenso de longa duração.

\section{$\overline{\text { Agradecimentos }}$}

Ao Conselho Nacional de Desenvolvimento Científico e Tecnológico- CNPq pelo apoio financeiro (Bolsa de doutorado pleno no exterior-GDE/Ciências sem Fronteiras) concedido a Grasiely Faccin Borges (202441/ 2011-3).

\section{Referências}

1. Caligiuri MA. Human natural killer cells. Blood 2008; 112:461-9.

2. Cooper MA, Fehniger TA and Caligiuri MA. The biology of human natural killer cell subsets. Trends Immunol 2001;22:633-40.

3. Barclay AN, Birkland ML, Brown MH, eds. The leukocyte antigen. London: Harcourt Brace Jovanovich 1997:136-229.

4. Godfrey DI, Hammond KJ, Poulton LD, Symth MJ, Baxter AG. NKT cells: facts, functions and fallacies. Immunol Today 2000;21(11):573-83.

5. Gharehbaghian A, Donaldson C, Newman J, Bannister G, Bradley BA. The correlation between the percent of CD3-CD56+ cells and NK precursor function. Iran J Allergy Asthma Immunol 2006;5(4):167-75. 
6. Shephard RJ, Shek, PN. Effects of exercise and training on natural killer cell counts and cytolytic activity: a meta-analysis. Sports Med 1999:28(3):177-95.

7. Timmons BW, Cieslak T. Human natural killer cell subsets and acute exercise: a brief review. Exerc Immunol Rev 2008;14(905):8-23.

8. Maghazachi AA. Role of chemokines in the biology of natural killer cells. Curr Top Microbiol Immunol 2010;341:37-58.

9. Ortaldo JR, Winkler-Pickett RT, Yagita H, Young HA. Comparative studies of CD3- and CD3+ CD56+ cells: examination of morphology, functions, $\mathrm{T}$ cell receptor rearrangement, and pore-forming protein expression. Cell Immunol 1991;136(2):486-495.

10. Carayol G, Robin C, Bourhis JH, Bennaceur-Griscelli A, Chouaib S, Coulombel L, et al. NK cells differentiated from bone marrow, cord blood and peripheral blood stem cells exhibit similar phenotype and functions. Eur J Immunol 1998;28(6):1991-2002.

11. O'Shea J, Ortaldo JR. The biology of natural killer cells: Insights into the molecular basis of function. In: Lewis CE, McGee JO, eds. The Natural Killer Cell. New York: Oxford University Press; 1992. p.1-40.

12. Van Elssen CHMJ, Vanderlocht J, Oth T et al. Inflammation restraining effects of prostaglandin E2 on natural killer-dendritic cell (NK-DC) interaction are imprinted during DC maturation. Blood 2011;118(9):2473-82.

13. Maghazachi AA. Role of chemokines in the biology of natural killer cells. Journal of Leukocyte Biology 2002;341(2):173-83.

14. Rama L, Teixeira AM, Matos A, Borges G, Henriques A, Gleeson $M$ et al. Changes in natural killer cell subpopulations over a winter training season in elite swimmers. Eur J Appl Physiol 2012; Sep 19 (prelo)

15. Aizawa $H$, Abo S, Aiba S. Epidermodysplasia verruciformis accompanied by large granular lymphocytosis. Report of a case and immunological studies. Arch Dermatol 1989;126:361-8.

16. Nagatomi R. The implication of alterations in leukocyte subset counts on immune function. Exercise Immunology Review 2006;12(1):5471.

17. Pizza FX, Flynn MG, Sawyer T, Brolinson PG, Starling RD, Andres FF et al. Run training versus cross-training: effect of increased training on circulating leukocyte subsets. Med Sci Sports Exerc 1995;27(3):355-62.
18. Shek PN, Sabiston BH, Buguet A, Radomski MW. Strenuous exercise and immunological changes: a multiple-time-point analysis of leukocyte subsets, CD4/ CD8 ratio, immunoglobulin production and NK cell response. Int J Sports Med 1995;16(7):466-74.

19. Walsh NP, Gleeson M, Shephard RJ. Position statement. Part one: Immune function and exercise. Exerc Immunol Review 2011;17:663.

20. Gleeson M, Bishop N, Oliveira M, McCauley $\mathrm{T}$. differences in immune variables and respiratory infection incidence in an athletic population. Exerc Immunol Review 2011; 44(0):122-35.

21. Kutza J, Kaye D, Murasko DM. Basal natural killer cell activity of young versus elderly humans. J Gerontol Biol Sci 1995; 50A(3): B110-B116.

22. McFarlin BK, Flynn MG, Campbell WW, Craig BA, Robinson JP, Stewart LK et al. Physical activity status, but not age, influences inflammatory biomarkers and toll-like receptor 4. J Gerontol A Biol Sci Med Sci 2006;61:388-93.

23. Shore S, Shephard R.J. Immune responses to exercise and training: a comparison between children and adults. Pediatr Exerc Sci 1998;10:210-26.

24. Anomasiri W, Sanguanrungsirikul S, Srikiatkhachorn A, Chuntavan P. Changes of immune system in military recruits after the training program. J Med Assoc Thai 2002;85 (Suppl 1):S327-S335.

25. Baj Z, Kantorski J, Majewska E, Zeman K, Pokoca L, Fornalczyk E, Tchórzewski H, et al. Immunological status of competitive cyclists before and after the training season. Int J Sports Med. 1994; 5(6):319-24.

26. Ferry A, Picard F, Duvallet A, Weill B, Rieu $M$. Changes in blood leucocyte populations induced by acute maximal and chronic submaximal exercise. Eur J Appl Physiol Occup Physiol 1990;59(6):435-42.

27. Gleeson M, McDonald WA, Cripps AW, Pyne DB, Clancy RL, Fricker PA, et al. The effect on immunity of long-term intensive training in elite swimmers. Clin Exp Immunol 1995;102(1):210-16.

28. Host CR, Norton KI, Olds TS, Lowe EL, Mulligan SP. The effects of altered exercise distribution on lymphocyte subpopulations. Eur J Appl Physiol1995;15:S127-30. 
29. La Perriere A, Antoni MH, Ironson G, Perry A, McCabe P, Klimas N, Helder L, et al. Effects of aerobic exercise training on lymphocyte subpopulations. Int J Sports Med1994;15(Suppl 3) S127-S130.

30. Peters E M, Robson PJ, Kleinveldt NC, Naicker VL, Jogessar VD. Hematological recovery in male ultramarathon runners: the effect of variations in training load and running time. J Sports Med Phys Fitness 2004;44(3):315-21.

31. Rhind SG, Shek PN, Shinkai S, Shephard RJ. Effects of moderate endurance exercise and training on in vitro lymphocyte proliferation, interleukin-2 (IL-2) production, and IL-2 receptor expression. Eur Appl Physiol Occup Physiol 1996;74(4):348-60.

32. Shore S, Shinkai S, Rhind S, Shephard RJ. Immune responses to training: how critical is training volume? J Sports Med Phys Fitness 1999;39(1):1-11.

33. Tvede N, Steensberg J, Baslund B et al. Cellular immunity in highly trained elite racing cyclists during periods of training with high and low intensity. Scand J Med Sci Sports 1991;1(3):163-6.

34. Unal M, Erdem S, Deniz G. The effects of chronic aerobic and anaerobic exercises $n$ lymphocyte subgroups. Acta Physiol Hung 2005;92(2):163-71.

35. Fry RW, Morton AR, Crawford GPM, Keast D. Cell numbers and in vitro responses of leucocytes and lymphocyte subpopulations following maximal exercise and interval training sessions of different intensities. Eur J Appl Physiol 1992;64:218-27.

36. Dong J, Tian Y-P, Gao Y-H, Li L-Q. Exercise-induced changes of $T$ lymphocytes subgroups and immune factors. Nan Fang Yi Ke Da Xue Bao 2010;30(10):2277-80.

37. Vose BM, Gallagher P, Moore M, Schofield PF. Specific and nonspecific lymphocyte cytotoxicity in colon carcinoma. Br J Cancer 1981;44:846-55.
38. Chung JS, Shin HJ, Lee EY, Cho GJ. Hypersensitivity to mosquito bites associated with natural killer cell-derived large granular lymphocyte lymphocytosis: a case report in Korea. Korean J Intern Med 2003;18(1):50-2.

39. MacKinnon LT. Overtraining effects on immunity and performance in athletes. Immunol Cell Biol 2000;78(5):502-9.

40. Suzuki S, Toyabe S, Moroda T et al. Circadian rhythm of leucocytes and lymphocytes subsets and its possible correlation with the function of the autonomic nervous system. Clin Exp Immunol 1997;110(3):500-8.

41. Kawate T, Abo T, Hinuma S. Kumagai K. Studies on the bioperiodicity of the immune response. II. Co-variations of murine $\mathrm{T}$ and $\mathrm{B}$ cells and arole of corticosteroid. J Immunol 1981;126:1364-7.

42. Hori T, Katafuchi T, Take S, Kaizuka Y, Ichijo T, Shimizu N.The hypothalamo-sympathetic nervous system modulates peripheral cellular immunity. Neurobiology (Bp) 1995;3:309-17.

43. Suzui M, Takeda K, Yagita H, Okumura K, Shek PN and Shephard RJ. Changes in the proportions of CD56dim and CD56bright natural killer cells during and after acute exercise. Med Sci Sports Exerc 2006;38: S413.

44. Gleeson M, Bishop NC. The T cell and NK cell immune response to exercise. Ann Transplant 2005:10(4)43-8.

45. Pedersen BK, Ullum H. NK cell response to physical activity: possible mechanisms of action. Med Sci Sports Exerc 1994;26:140-6.

46. Shinkai S, Watanabe S, Assai H, Shek PN. Cortisol response to exercise and post-exercise suppression of blood lymphocyte subset counts. Int J Sports Med 1996; 17(8):597603. 